\title{
A REMARK ON THE PRINCIPLE OF ZERO UTILITY
}

\author{
By Hans U. Gerber \\ University of Lausanne, Switzerland
}

Let $u(x)$ be a utility function, i.e., a function with $u^{\prime}(x)>0, u^{\prime \prime}(x)<0$ for all $x$. If $S$ is a risk to be insured (a random variable), the premium $P=P(x)$ is obtained as the solution of the equation

$$
u(x)=E[u(x+P-S)]
$$

which is the condition that the premium is fair in terms of utility. It is clear that an affine transformation of $u$ generates the same principle of premium calculation. To avoid this ambiguity, one can standardize the utility function in the sense that

$$
u(y)=0, \quad u^{\prime}(y)=1
$$

for an arbitrarily chosen point $y$. Alternatively, one can consider the risk aversion

$$
r(x)=-u^{\prime \prime}(x) / u^{\prime}(x)
$$

which is the same for all affine transformations of a utility function.

Given the risk aversion $r(x)$, the standardized utility function can be retrieved from the formula

$$
u(x)=\int_{y}^{x} \exp \left(-\int_{y}^{z} r(u) d u\right) d z .
$$

It is easily verified that this expression satisfies (2) and (3).

The following lemma states that the greater the risk aversion the greater the premium, a result that does not surprise.

LEMMA. Let $u_{1}(x)$ and $u_{2}(x)$ be two utility functions with corresponding risk aversions $r_{1}(x), r_{2}(x)$. Let $P_{i}$ denote the premium that is generated by $u_{i}(i=1,2)$. If $r_{1}(x) \geqslant r_{2}(x)$ for all $x$, it follows that $P_{1}(w) \geqslant P_{2}(w)$ for any risk $S$ and all $w$.

Proof. $P_{i}=P_{i}(w)$ is obtained as the solution of the equation

$$
u_{i}(w)=E\left[u_{i}\left(w+P_{i}-S\right)\right], \quad i=1,2 .
$$

We standardize $u_{1}$ and $u_{2}$ such that

$$
u_{i}(w)=0, u_{i}^{\prime}(w)=1
$$

Using (4), with $y=w$, we can express $u_{i}$ in terms of $r_{i}$. Since $r_{1}(x) \geqslant r_{2}(x)$ for all $x$, it follows that

$$
u_{1}(x) \leqslant u_{2}(x) \text { for all } x
$$

ASTIN BULLETIN Vol. 13, No. 2 
Using (5), (6), (7) we see that

$$
E\left[u_{2}\left(w+P_{2}-S\right)\right]=E\left[u_{1}\left(w+P_{1}-S\right)\right] \leqslant E\left[u_{2}\left(w+P_{1}-S\right)\right]
$$

Since $u_{2}$ is an increasing function, the inequality between the first term and the last term means that $P_{1} \geqslant P_{2}$.

Q.E.D.

The lemma has some immediate consequences:

APPLICATION 1. The exponential premium, $P=(1 / a) \log E\left[e^{a s}\right]$, is an increas ing function of the parameter $a$.

Proof. Let $a_{1}>a_{2}$. Use the lemma in the special case $r_{i}(x)=a_{i}$ (constant) to see that the exponential premium (parameter $a_{1}$ ) exceeds the exponential premium (parameter $a_{2}$ ).

Q.E.D.

Application 2. Suppose that $r(x)$ is a nonincreasing function. Then $P=P(x)$ as determined from (1) is a nonincreasing function of $x$ for any risk $S$.

Proof. Let $h>0$. Use the lemma with $r_{1}(x)=r(x), r_{2}(x)=r(x+h)$ to see that $P(x) \geqslant P(x+h)$.

Q.E.D.

REMARKS. (1) The last two proofs are simpler than the original proofs given by Gerber (1974, p. 216) for the first application and by Leepin (1975, pp. 31-35) for the second application.

(2) For a small risk $S$ (i.e., a random variable $S$ with a narrow range) $P(x)$ is approximately $E[S]+r(x) \operatorname{var}[S] / 2$. Thus the converse of the Lemma $\left(P_{1}(w) \geqslant\right.$ $P_{2}(w)$ for all $S$ implies that $\left.r_{1}(x) \geqslant r_{2}(x)\right)$ is trivial.

(3) In Pratt's terminology (1964) the premium $P$ is a (negative) bid price. However, Pratt's discussion focusses essentially on (what he calls) the insurance premium $Q$, which is defined as the solution of the equation

$$
u(x-Q)=E[u(x-S)]
$$

and which should be interpreted as the largest premium someone with fortune $x$ and liability $S$ is willing to pay for full coverage. The counterpart of the Lemma (with $P_{i}(w)$ replaced by $\left.Q_{i}(w)\right)$ has been discussed by Pratt $(1964$, p. 128$)$. A short proof of this counterpart is obtained if one standardizes $u_{1}$ and $u_{2}$ such that

$$
u_{i}\left(w-Q_{1}\right)=0, \quad u_{i}^{\prime}\left(w-Q_{1}\right)=1 .
$$

Details are left to the reader.

\section{REFERENCES}

Gerber, H. U. (1974) On Additive Premium Calculation Principles. Astin Bulletin 7, 215-222. LEEPIN, P. (1975) Ueber die Wahl von Nutzenfunktionen für die Bestimmung von Versicherungsprämien. Mitteilungen der Vereinigung schweizerischer Versicherunsmathematiker 75, 27-45.

PratT, J. W. (1964). Risk Aversion in the Small and in the Large. Econometrica 32, 122-136. 